University of Nebraska - Lincoln

DigitalCommons@University of Nebraska - Lincoln

July 2007

\title{
Linear, redox modified DNA probes as electrochemical DNA sensors
}

Francesco Ricci

University of California, Santa Barbara, California

Rebecca Lai

University of Nebraska - Lincoln, rlai2@unl.edu

Kevin W. Plaxco

University of California, Santa Barbara, California

Follow this and additional works at: https://digitalcommons.unl.edu/chemistrylai

Part of the Chemistry Commons

Ricci, Francesco; Lai, Rebecca; and Plaxco, Kevin W., "Linear, redox modified DNA probes as electrochemical DNA sensors" (2007). Rebecca Lai Publications. 2.

https://digitalcommons.unl.edu/chemistrylai/2

This Article is brought to you for free and open access by the Published Research - Department of Chemistry at DigitalCommons@University of Nebraska - Lincoln. It has been accepted for inclusion in Rebecca Lai Publications by an authorized administrator of DigitalCommons@University of Nebraska - Lincoln. 
Published in Chemical Communications (2007), no. 36, pp. 3768-3770; doi 10.1039/b708882e

Copyright (C) 2007 The Royal Society of Chemistry. Used by permission. http://www.rsc.org/chemcomm

Submitted June 15, 2007; accepted June 20, 2007; published online July 5, 2007.

Supplementary information follows the "References," including experimental procedures, controlling probe surface density, sensor equilibration time and specificity, the effect of target length and bulk on signaling, electron transfer rate measurements, and probe density effects on signaling. It is also available online at doi 10.1039/b708882e

\title{
Linear, redox modified DNA probes as electrochemical DNA sensors
}

\author{
Francesco Ricci ${ }^{a c}$, Rebecca Y. Lai ${ }^{a b}$ and Kevin W. Plaxco ${ }^{a}$ \\ ${ }^{a}$ Department of Chemistry and Biochemistry, University of California, Santa Barbara, California 93106, USA \\ ${ }^{\mathrm{b}}$ Department of Physics and Institute for Polymers and Organic Solids, University of California, Santa Barbara, California 93106, USA \\ ${ }^{\mathrm{c}}$ On leave from the University of Rome Tor Vergata, Dipartimento di Scienze e Tecnologie Chimiche, Via della Ricerca Scientifica, 00133, Rome, Italy
}

\begin{abstract}
We show here that hybridization-linked changes in the dynamics of a redox-modified, electrode-bound linear (as opposed to stem-loop) probe DNA produce large changes in Faradaic current, allowing for the ready detection of target oligonucleotides.
\end{abstract}

E-DNA sensors, which consist of a redox-tagged stemloop DNA covalently attached to an interrogating electrode, are the electrochemical equivalents of optical molecular beacons. ${ }^{1-9}$ We show here, however, that unlike molecular beacons, which rely on a rigid, binding-induced conformational change (to segregate a fluorophore-quencher pair), ${ }^{10-12} \mathrm{E}-$ DNA signaling arises due to binding-induced changes in the dynamics of the probe DNA. We do so by demonstrating that hybridization-linked changes in the dynamics of an electrodebound linear (as opposed to stem-loop) probe DNA efficiently support E-DNA signaling. That is, whereas a large Faradaic current is observed from a redox-modified, single-stranded DNA probe, this current is reduced upon hybridization to the appropriate target DNA sequence due to changes in the rate with which the terminal redox label collides with the electrode surface (Figure 1).

We have fabricated E-DNA sensors using a 27-base linear probe sequence that, in order to facilitate direct comparison with earlier studies, is directly analogous to a previously characterized stem-loop E-DNA sensor ${ }^{9,13}$ save that the five base sequences at the two termini are identical and thus do not form a double stranded stem. In the absence of target, the sensor gives rise to a sharp, well-defined AC voltammetry peak consistent with the $\sim-0.26 \mathrm{~V}$ (vs. $\mathrm{Ag} / \mathrm{AgCl}$ ) formal potential of the methylene blue redox moiety employed (Figure 2). Upon hybridization to a fully complementary, 17-base target

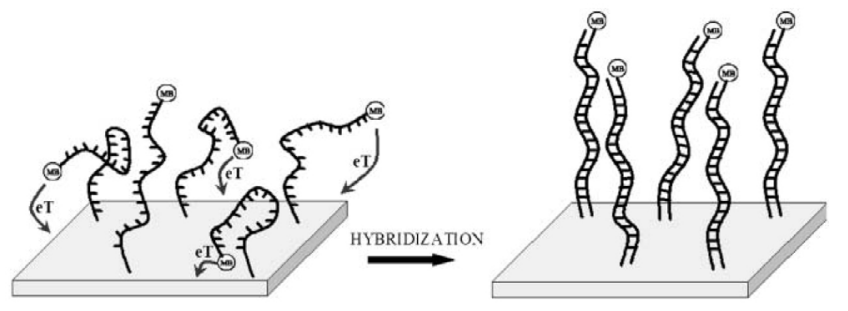

Figure 1. E-DNA signaling arises due to hybridization-induced changes in probe dynamics (rather than to a conformational change per se) and thus redox-modified linear probe DNAs serve as effective E-DNA sensors. The Faradaic current arising from such a linear probe DNA is significantly reduced in the presence of a complementary target sequence because, as demonstrated here, hybridization reduces the rate with which the terminal redox tag collides with the electrode surface and transfers electrons. this current is significantly reduced. Furthermore, because the observed signal change arises due to a hybridization-specific change in DNA dynamics (as opposed to the simple adsorption of mass or charge to the sensor surface), we can readily observe this change even when the sensor is challenged with complex, multi-component sample matrices, such as targetdoped blood serum (Figure 2, right). Finally, like the original stem-loop E-DNA architecture, the linear-probe E-DNA sensor is label-free and reusable: a $30 \mathrm{sec}$ wash in room temperature distilled water or (after deployment in blood serum) room temperature detergent solution is enough to regenerate $>97 \%$ original sensor current (Figure 2).

The signaling characteristics of linear probe E-DNA sensors are improved relative to those of the equivalent stem-loop sensor. Whereas a linear probe E-DNA sensor exhibits an 85\% signal reduction at a given target concentration (Figure 2), the equivalent stem loop sensor exhibits only $71 \%$ signal suppression at this target concentration. ${ }^{9}$ We presume this difference

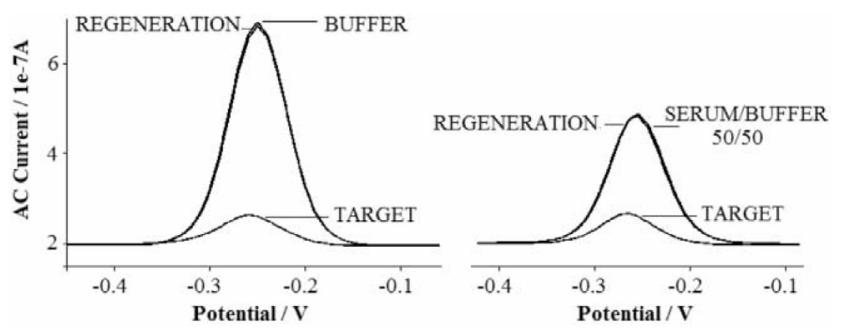

Figure 2. Linear-probe E-DNA sensors respond well in either (left) buffer or (right) $50 \%$ blood serum. And while the currents observed in serum are lower, the signal suppression observed in serum $(77 \%)$ is quite similar to that obtained in buffer $(85 \%)$ and equivalent sensor regeneration $(>97 \%)$ is observed under both conditions. The reduced currents observed in serum may be due to the greater viscosity and/or the reduced ionic strength of this medium, which would reduce collision rates and electron transfer efficiency; no similar drop-off is observed for stem-loop sensors, ${ }^{3}$ presumably because the stem structure fixes the MB near the surface, rendering its electron transfer rate relatively independent of these effects. The very similar gains observed in serum and in buffer suggest that none of the hundreds of proteins that have been identified in serum to date affect sensor performance. These experiments were conducted after $\sim 30 \mathrm{~min}$. incubation with $200 \mathrm{nM}$ of a 17-base, fully complementary target. Regeneration is achieved with a $30 \mathrm{sec}$, room temperature wash in (left) distilled water or (right) $10 \%$ sodium dodecyl sulfate. 

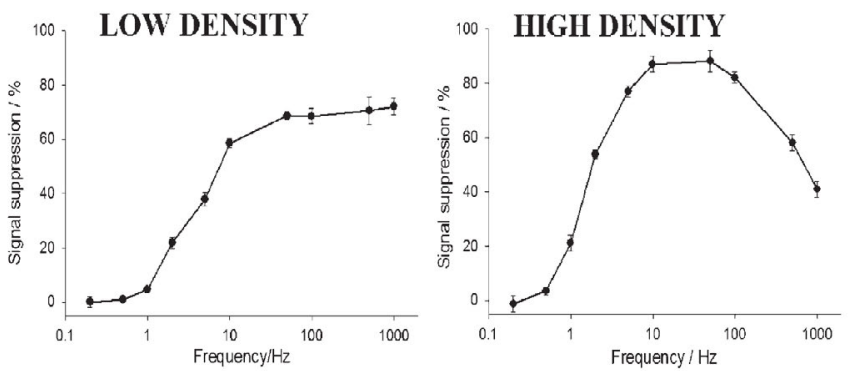

Figure 3. Sensor response is a strong function of the ACV frequency employed to probe electron transfer, supporting the collisional mechanism proposed here. The signal suppression observed with lower-density sensors (left) rises rapidly above $\sim 0.5 \mathrm{~Hz}$ before saturating at $\sim 10 \mathrm{~Hz}$. This presumably occurs because, at lower AC frequencies, the MB moiety on both single-stranded and more rigid, double-stranded probes have sufficient time to collide with the electrode and transfer electrons (and thus the difference in the current arising from free and target-bound probes is reduced). In contrast, the signal change associated with higher-density sensors (right) rises at lower frequencies and then decreases again above $\sim 50 \mathrm{~Hz}$. We presume the latter fall-off occurs because, under these conditions, the collision dynamics of even single-stranded probes do not support efficient electron transfer (of note, no similar drop-off is observed for stem-loop sensors of any density, ${ }^{9}$ presumably because the stem structure fixes the MB near the surface, ensuring an extremely rapid collision rate). Shown are the signal ratios between the current obtained in absence and presence of $200 \mathrm{nM}$ of a $17-\mathrm{base}$, fully complementary target after 30 min equilibration. The illustrated error bars represent the standard deviation of measurements conducted with three independently fabricated sensors.

arises because, in contrast to the stem-loop probe, the target binding to the linear probe is not coupled to a competing equilibrium (stem formation) and is thus favored. The response time and specificity of the E-DNA sensor are, in contrast, not significantly influenced by the geometry of the probe DNA. For example, we observe the same ratio of suppression obtained with the fully complementary target to that obtained with a three base mismatched target for both stem-loop and linear probe sensors (e.g., $\sim 1.17$ at a probe density of $1.6 \times$ $10^{12}$ molecules $\mathrm{cm}^{-2}$-Table SI1 and ref. 9), and the equilibration times of both classes of sensors are quite rapid (near complete equilibration is achieved in $<5 \mathrm{~min}$. for lower density sensors-Figure SI1 and ref. 9). As with the original EDNA architecture, ${ }^{9}$ the length and structure of the target affect linear-probe E-DNA signaling, with longer and/or bulkier targets producing greater signal suppression (Table SI2). Finally, as with its stem-loop predecessor, the signals observed from the linear-probe sensor are quite reproducible in both the absence and presence of the 17-base fully complementary target (RSD $<10 \%$, and $3 \%$ respectively, $n=3$ ) (Table SI1) and the sensor is relatively stable (24-48 $\mathrm{h}$ in buffer at room temperature, data not shown).

E-DNA signal gain is a function of the density of the DNA probes on the sensor surface, an effect that provides insights into the E-DNA sensing mechanism. By varying the probe DNA concentrations employed during sensor fabrication (over the range 0.005 to $2 \mu \mathrm{M}$ ) we can control this important variable and can readily and reproducibly fabricate linear-probe sensors of probe densities from $1.2 \times 10^{10}$ to $1.6 \times 10^{12}$ molecules $\mathrm{cm}^{-2}$ (assuming perfect electron transfer efficiency) (see Figure SI2). This range of probe densities corresponds to mean probe-to-probe separations of $\sim 97$ to $\sim 8 \mathrm{~nm}$. (Given, however, that perfect transfer efficiency is unlikely, these numbers presumably overestimate the actual probe-to-probe distance.) A dramatic rise in signal suppression is observed as the mean probe separation drops (Figure SI3), presumably because, with increased crowding, the dynamics of target-probe duplexes are reduced preferentially, increasing the binding-induced change in electron transfer efficiency.
The ACV frequency dependence of the response of linear-probe sensors (Figure 3) provides further evidence for this collisional model of E-DNA signaling. At low ACV frequencies no significant signal suppression is observed, presumably because the collision rates of both unhybridized and hybridized probes are rapid enough to support efficient electron transfer under these conditions. The target-induced signal suppression then increases as the $\mathrm{ACV}$ frequency rises until, for lower-density sensors, it plateaus at $\sim 10 \mathrm{~Hz}$. At still higher frequencies the suppression observed for higher-density sensors once again falls. We presume this occurs because, at higher probe densities, the collision rate of the single-stranded probe is slow enough that electron transfer from unbound probes is also inhibited under these conditions. In support of this collision-limited signaling mechanism, we find that the rate of electron transfer slows by approximately an order of magnitude upon target binding (see Figure SI4).

All of the groups responsible for the initial development of E-DNA sensors employed stem-loop DNA probes, ${ }^{1-9,14,15}$ presumably due to the misconception, ${ }^{1-3,9,14}$ shared by us, that, by analogy to molecular beacons, a specific conformational (i.e., geometric) change is required in order to support robust signaling. We have shown here, however, that bindinginduced changes in DNA dynamics are sufficient to support E-DNA signaling. Indeed, although the stem-loop probe provides a more controlled and predictable structure (which in turn appears to minimize the effects of changing viscosity and/ or ionic strength on the absolute signal current), ${ }^{3}$ the linearprobe sensor exhibits improved signal gain over its stem-loop counterpart. Moreover, like these counterparts, linear-probe E-DNA sensors are label free, reusable, sequence specific and selective enough to employ directly in complex sample matrices such as blood serum, thus rendering them well suited for clinical applications.

\section{Acknowledgments}

The authors acknowledge Brian Piorek's efforts in initiating this project. The authors also acknowledge the US Ar- 
my's Institute for Collaborative Biotechnologies (Contract Number DAAD 19-03-D-0004) and the Center for Nanoscience Innovation for Defense (DMEA90-02-2-0215) for financial support.

\section{References}

1 R. Y. Lai, S.-H. Lee, H. T. Soh, K. W. Plaxco and A. J. Heeger, Langmuir, 2006, 22, 1932 .

2 C. Fan, K. W. Plaxco and A. J. Heeger, Proc. Natl. Acad. Sci. U. S. A., 2003, 100, 9134 .

3 A. A. Lubin, R. Y. Lai, B. R. Baker, A. J. Heeger and K. W. Plaxco, Anal. Chem., 2006, 78(16), 5671 .

4 Y. Xiao, B. D. Piorek, K. W. Plaxco and A. J. Heeger, J. Am. Chem. Soc., 2005, 127, 17990 .

5 B. R. Baker, R. Y. Lai, M. S. Wood, E. H. Doctor, A. J. Heeger and K. W. Plaxco, J. Am. Chem. Soc., 2006, 128, 3138 .

6 C. E. Immoos, S. J. Lee and M. W. Grinstaff, ChemBioChem, 2004, 5, 1100 .
7 C. E. Immoos, S. J. Lee and M. W. Grinstaff, J. Am. Chem. Soc., 2004, 126, 10814 .

8 T. Mao, C. Luo and Q. Ouyang, Nucleic Acids Res., 2003, 31, 108.

9 F. Ricci, R. Y. Lai, A. J. Heeger, K. W. Plaxco and J. J. Sumner, Langmuir, 2007, 23(12), 6827.

10 Y. W. C. Cao, R. C. Jin and C. A. Mirkin, Science, 2002, 297, 1536 .

11 B. S. Gaylord, A. J. Heeger and G. C. Bazan, Proc. Natl. Acad. Sci. U. S. A., 2002, 99, 10954.

12 E. Palecek, Trends Biotechnol., 2004, 22, 55.

13 R. Y. Lai, E. T. Lagally, S.-H. Lee, H. T. Soh, K. W. Plaxco and A. J. Heeger, Proc. Natl. Acad. Sci. U. S. A., 2006, 103, 4017.

14 R. Lai, K. W. Plaxco and A. J. Heeger, Anal. Chem., 2007, 79(1), 229 .

15 J. J. Sumner, K. S. Weber, L. A. Hockett and S. E. Creager, J. Phys. Chem. B, 2000, 104, 7449 .

\section{Supplementary Information}

\section{MATERIALS AND METHODS}

\section{Probe DNA and Sensor Fabrication}

Reagent grade chemicals, including 6-mercapto-1-hexanol $\left(\mathrm{C}_{6}-\mathrm{OH}\right)$, iron-supplemented fetal calf-serum, sulfuric acid (all from Sigma-Aldrich, St. Louis, MO), potassium phosphate monobasic, dibasic, and sodium chloride (Fisher Scientific) were used without further purification. A 27-base, 3' thiol-, 5' methylene blue (MB)-modified oligonucleotide was obtained from Biosearch Technologies (Novato, CA) and employed as the probe DNA. The 17 internal bases of this sequence are complementary to the gyrB gene of Salmonella. Flanking the gyrB sequence are two copies of a 5-base element identical to the 3' end of the stem-loop structure we have employed in previous E-DNA studies. ${ }^{1,2}$ The MB redox moiety was conjugated to the 3' end of the oligonucleotide via succinimide ester coupling to a 3' amino modification (MB-NHS, EMP Biotech, Berlin) producing the probe sequence: 5'-HS- $\left(\mathrm{CH}_{2}\right)_{6}$-CGTCAATCTTCTATTTCTCCACACTGC- $\left(\mathrm{CH}_{2}\right)_{7}$-NH-MB-3'.

The sensors were fabricated on rod gold disk electrodes (2.0 mm diameter, BAS, West Lafayette, IN). The electrodes were prepared by polishing with diamond and alumina (BAS), followed by sonication in water, and electrochemical cleaning (a series of oxidation and reduction cycles in $0.5 \mathrm{M} \mathrm{H}_{2} \mathrm{SO}_{4}$, $0.01 \mathrm{M} \mathrm{KCl} / 0.1 \mathrm{M} \mathrm{H}_{2} \mathrm{SO}_{4}$, and $0.05 \mathrm{M} \mathrm{H}_{2} \mathrm{SO}_{4}$ ). The effective area of the electrode was determined from the charge associated with the gold oxide reduction peak obtained after the cleaning process and a roughness factor (the ratio of the real to apparent or geometric electrode area) of $\sim 1.11$ was typically observed. The probe DNA was immobilized onto these freshly cleaned electrodes by incubating for one hour in a so- lution of $1 \mu \mathrm{M}$ TCEP (Tris(2-carboxyethyl) phosphine hydrochloride) in $100 \mathrm{mM} \mathrm{NaCl} / 10 \mathrm{mM}$ potassium phosphate $\mathrm{pH}$ 7 buffer containing the appropriate concentrations of probe DNA. Different probe densities were obtained by controlling the concentration of probe DNA employed during the fabrication process. Following probe immobilization the electrode surface was rinsed with distilled, di-ionized water and subsequently passivated with $1 \mathrm{mM}$ 6-mercaptohexanol in $1 \mathrm{M}$ $\mathrm{NaCl} / 10 \mathrm{mM}$ potassium phosphate buffer, $\mathrm{pH} 7$, for $2 \mathrm{hr}$. and followed by further rinsing with deionized water.

\section{Target DNA Sequences}

We employed target DNA sequences of varying lengths and structures (Table S1), all of which were obtained via commercial synthesis (Sigma Genosys, St. Luis, MO). The target sequences were as follows:

ST-25 (normal target, 17 bases, 5'- GTG GAG AAA TAG

AAG AT - 3'); ST-25-3M1 (three T-T mismatched target,

17 bases, 5'-GTG GAG TTT TAG AAG AT - 3'); LT-27 (27

bases target, 5'-GCAGT GTG GAG AAA TAG AAG AT

TGACG- 3'); MLL-38 (long target with a structured loop tail, 38 bases, 5'-GCGTTTTTCGC GCAGT GTG GAG AAA TAG AAG ATTGACG - 3').

\section{Electrochemical Measurements}

The sensor response was measured by incubating the electrodes in $200 \mathrm{nM}$ of the appropriate target DNA. The sensors were interrogated at different intervals in the same target solution until a stable current peak was obtained. The ratio between the stabilized current peak in the presence of target DNA and the current peak in absence of target DNA gives the measure of the signal suppression caused by the target. Before being used to detect the next target the electrodes were 
rinsed with deionized water and interrogated in target free buffer. This also provides a measure of the extent to which each sensor can be regenerated. When fetal calf serum was used it was diluted 1:1 with buffer solution. Prior to interrogation, the electrodes were incubated for $\sim 30 \mathrm{~min}$. in the sample lacking exogenously added target. The target was added only when the sensor had fully equilibrated/stabilized as determined by stable peak currents. The sensor was then allowed to incubate in the presence of the target for $\sim 30 \mathrm{~min}$. before voltammetric measurements were conducted directly in the sample. Sensor regeneration was achieved via immersing in 10\% SDS for 2 min followed by rinsing with deionized water. Regeneration was verified by ACV collected after $30 \mathrm{~min}$. immersion in target-free buffer/serum solution.

All measurements were performed at room temperature using a CHI 730B Electrochemical Workstation (CH Instruments, Austin, TX). Alternating current voltammograms (ACV) were recorded from $-0.05 \mathrm{~V}$ to $-0.44 \mathrm{~V}$ vs. an $\mathrm{Ag} / \mathrm{AgCl}$ $(3 \mathrm{M} \mathrm{NaCl})$ reference electrode in a standard cell with a platinum counter electrode. All experiments were conducted using a $25 \mathrm{mV} \mathrm{AC} \mathrm{potential} \mathrm{at} \mathrm{a} \mathrm{frequency} \mathrm{of} 10 \mathrm{~Hz}$ unless otherwise stated. All experiments were conducted in $1 \mathrm{M} \mathrm{NaCl} / 10$ $\mathrm{mM}$ potassium phosphate buffer, $\mathrm{pH}$ 7. Probe surface density (i.e., the number of electroactive probe DNA moles per unit area of the electrode surface, $N_{\text {tot }}$ ) was determined using a previously established relationship with ACV peak current ${ }^{3}$ described in equation (1):

$$
\text { (Eq. 1) } I_{a v g}\left(E_{0}\right)=2 n f F N_{t o t} \frac{\sinh \left(n F E_{a c} / R T\right)}{\cosh \left(n F E_{a c} / R T\right)+1}
$$

where: $I_{\text {avg }}\left(E_{0}\right)$ is the average ac peak current in voltammogram, $n$ is the number of electrons transferred per redox event (with our MB label $n=2$ ), $F$ is the Faraday current, $R$ is the universal gas constant, $T$ is the temperature, $E_{\mathrm{ac}}$ is the peak amplitude, and $f$ is the frequency of the applied AC voltage perturbation. Perfect transfer efficiency was assumed (i.e., that all of the redox moieties participate in electron transfer); errors in this assumption would lead us to underestimate probe density. Experimentally, ${ }^{4}$ different frequencies were used (5, 10,50 , and $100 \mathrm{~Hz}$ ) and the average current peak was calculated so as to give the value of $N_{\text {tot }}$.

\section{Electron Transfer Rate Measurements}

The study of electron transfer rate was performed using $\mathrm{ACV}$ at frequencies ranging from 0.1 to $10,000 \mathrm{~Hz}$. The peak current was then evaluated for each frequency and the ratio between the current peak and the baseline current was plotted vs. the measurement frequency. ${ }^{4,5}$ The study was performed before and after the hybridization with $200 \mathrm{nM}$ target DNA.

\section{Notes and references}

1 C. Fan, K.W. Plaxco and A.J. Heeger, Proc. Natl. Acad. Sci. USA, 2003, 100, 9134.

2 R.Y. Lai, E.T. Lagally, S.-H. Lee, H.T. Soh, K.W. Plaxco and A.J. Heeger, Proc. Natl. Acad. Sci. USA, 2006, 103, 4017.

3 S.D. O'Connor, G.T. Olsen and S.E. Creager, J. Electroanal. Chem. 1999, 466, 197.

4 S.E. Creager and T.T. Wooster, Anal. Chem. 1998, 70, 4257.

5 J.J. Sumner, K.S. Weber, L.A. Hockett and S.E. Creager, J. Phys. Chem. B 2000, 104, 7449.

6 P. Gong, C.-Y. Lee, L.J. Gamble, D.G. Castner and D.W. Grainger, Anal. Chem. 2006, 78(10), 3326.

7 A.W. Peterson, R.J. Heaton and R.M. Georgiadis, Nucleic Acids Res. 2001, 29, 5163.

8 A.W. Peterson, L.K. Wolf, R.M. Georgiadis, J. Am. Chem. Soc. 2002, 124, 14601.

9 F. Ricci, R.Y. Lai, A.J. Heeger, K.W. Plaxco, K. W. and J.J. Sumner, Langmuir, 2007, 23(12), 6827.

Table SI1 Summary of E-DNA sensor performance.

\begin{tabular}{|c|c|c|c|c|c|c|c|}
\hline Sensor & $\begin{array}{c}\text { Probe DNA } \\
\text { concentration } \\
\text { used during } \\
\text { sensor } \\
\text { fabrication } \\
(\mu \mathrm{M}) \\
\end{array}$ & $\begin{array}{l}\text { Probe density } \\
\left.\text { (molecules } / \mathrm{cm}^{2}\right)\end{array}$ & $\begin{array}{c}\text { Mean } \\
\text { probe-to- } \\
\text { probe } \\
\text { separation } \\
(\mathrm{nm})\end{array}$ & $\begin{array}{c}\mathbf{A C V} \\
\mathbf{i}_{p}(\mathbf{n A})\end{array}$ & $\begin{array}{c}\text { Signal } \\
\text { suppression } \\
\text { with ST-25 } \\
(\%)\end{array}$ & $\begin{array}{l}\text { Selectivity } \\
\text { ratio }^{\mathrm{a}}\end{array}$ & $\begin{array}{c}\text { Average } \\
\text { regeneration }^{\mathrm{b}} \\
(\%)\end{array}$ \\
\hline HIGH DENSITY & 0.5 & $1.6 \times 10^{12}$ & 8.0 & 440 & $85 \pm 2$ & 1.17 & $97 \pm 2$ \\
\hline $\begin{array}{l}\text { MEDIUM } \\
\text { DENSITY }\end{array}$ & 0.1 & $4.2 \times 10^{11}$ & 15.4 & 110 & $60 \pm 2$ & 1.05 & $98 \pm 3$ \\
\hline LOW DENSITY & 0.02 & $5.1 \times 10^{10}$ & 44.5 & 10 & $58 \pm 3$ & 1.00 & $94 \pm 3$ \\
\hline
\end{tabular}

\footnotetext{
${ }^{a}$ Ratio between the signal suppression obtained with the complementary target (ST-25) and a three-bases mismatched target (ST-25-3M1).

${ }^{\mathrm{b}}$ Signal recovery after target hybridization obtained rinsing with deionised water and testing in target free buffer. Values are the average and 
Table SI2 Effects of Target Length and Bulk on Signal Suppression

\begin{tabular}{|c|c|c|c|}
\hline DNA TARGET & ST-25 & LT-27 & MLL-38 \\
\hline $\begin{array}{l}\text { BINDING } \\
\text { SCHEME }^{a}\end{array}$ & 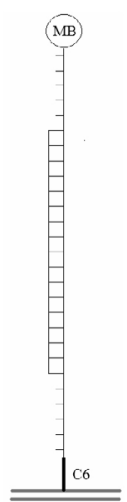 & 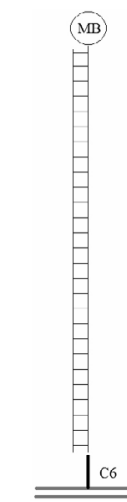 & 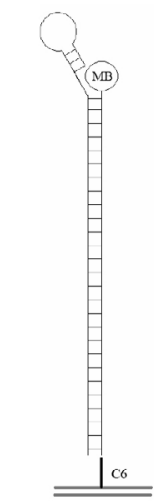 \\
\hline $\begin{array}{c}\text { HIGH DENSITY } \\
1.6 \times 10^{12} \text { molecules } / \mathrm{cm}^{2}\end{array}$ & $85 \pm 2$ & $94 \pm 1$ & $91 \pm 2$ \\
\hline $\begin{array}{l}\text { MEDIUM DENSITY } \\
4.2 \times 10^{11} \text { molecules } / \mathrm{cm}^{2}\end{array}$ & $60 \pm 2$ & $88 \pm 3$ & $97 \pm 3$ \\
\hline $\begin{array}{c}\text { LOW DENSITY } \\
5.1 \times 10^{10} \text { molecules } / \mathrm{cm}^{2}\end{array}$ & $58 \pm 3$ & $88 \pm 3$ & $100 \pm 1$ \\
\hline
\end{tabular}

${ }^{a}$ See table $\mathrm{S} 1$ for sequences.

b $\%$ values of signal suppression as a result of target hybridization are the average and standard deviation of measurements performed with four independent sensors.
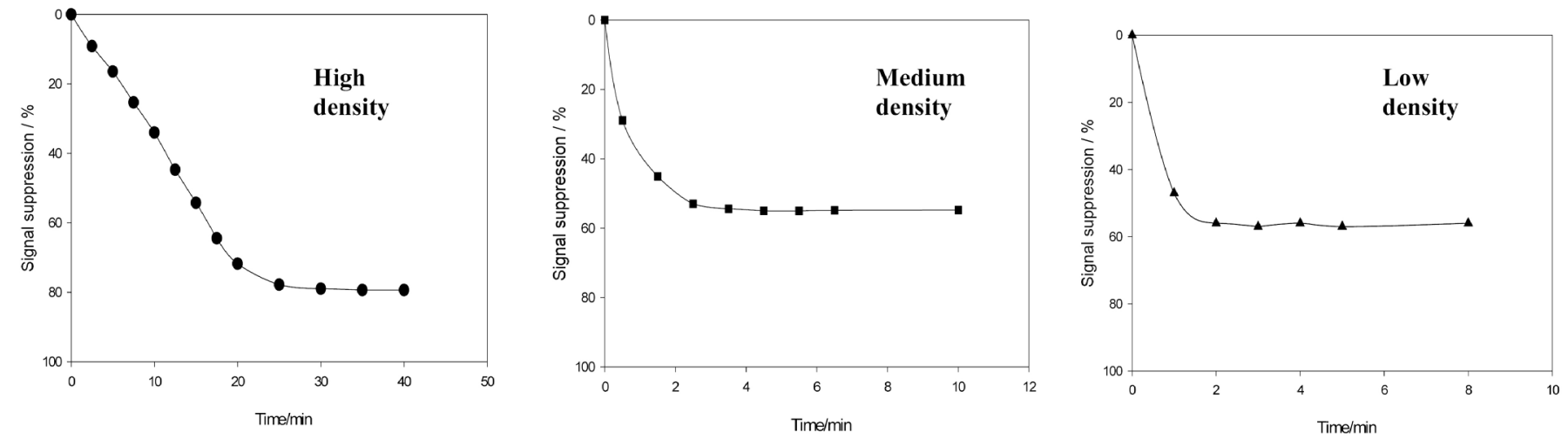

Figure SI1. Sensor equilibration time is dependant on probe density. Shown is the response to the presence of 200 nM target DNA (ST-25) of three representative sensors with high $\left(1.6 \times 10^{12}\right.$ molecules $\left./ \mathrm{cm}^{2}\right)$ medium $\left(4.2 \times 10^{11}\right.$ molecules $\left./ \mathrm{cm}^{2}\right)$ and low $\left(5.1 \times 10^{10} \mathrm{molecules} / \mathrm{cm}^{2}\right)$ density. 


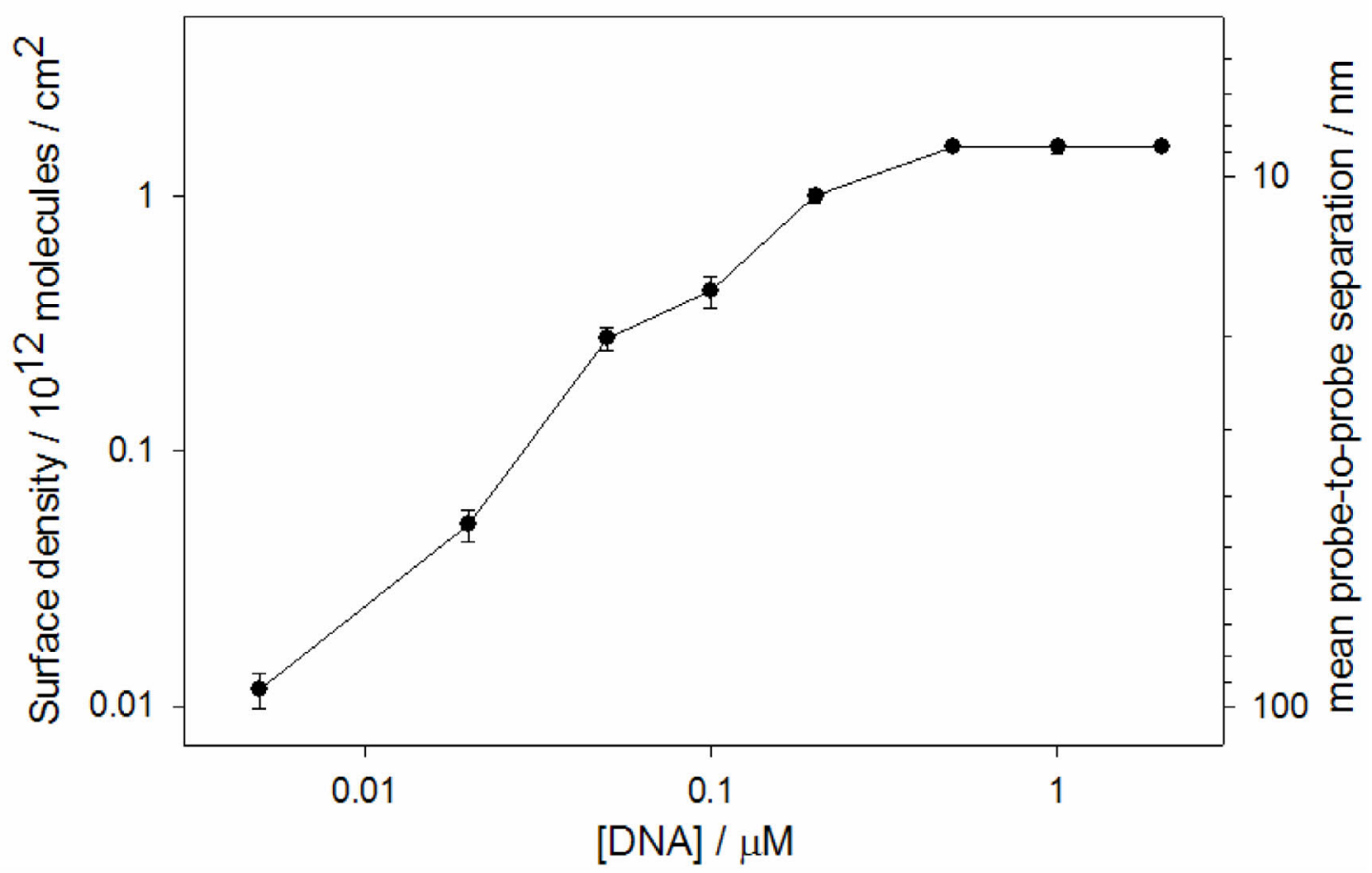

Figure SI2. Probe density affects the E-DNA signaling and equilibration time and provides insights into the details of the sensing mechanism. We have controlled probe density by changing the concentration of probe DNA employed during sensor fabrication. Using this approach we can readily and reproducibly fabricate linear-probe sensors with probe densities ranging from $1.2 \times 10^{10}$ to $1.6 \times 10^{12}$ molecules $/ \mathrm{cm}^{2}$ (corresponding to packing of $2.0 \times 10^{-14}$ to $2.6 \times 10^{-12} \mathrm{~mol} / \mathrm{cm}^{2}$ ) by employing probe DNA concentrations from 0.005 to $2 \mu \mathrm{M}$ during fabrication. Attempts to fabricate sensors with lower probe densities fail to produce stable, active films and no electrochemical signal is detectable (data not shown). The observed probe density increases monotonically with increasing probe concentration until a density of $\sim 1.6 \times 10^{12}$ molecules $/ \mathrm{cm}^{2}$ is obtained, after which no further increases in probe density are observed. Similar saturating probe densities have been reported by others using comparable length linear probes ${ }^{6-8}$ and by similar approach using an equivalent stem-loop probe. ${ }^{9}$ Values and error bars respectively represent the average and standard deviation of measurements conducted with three independently fabricated sensors. 


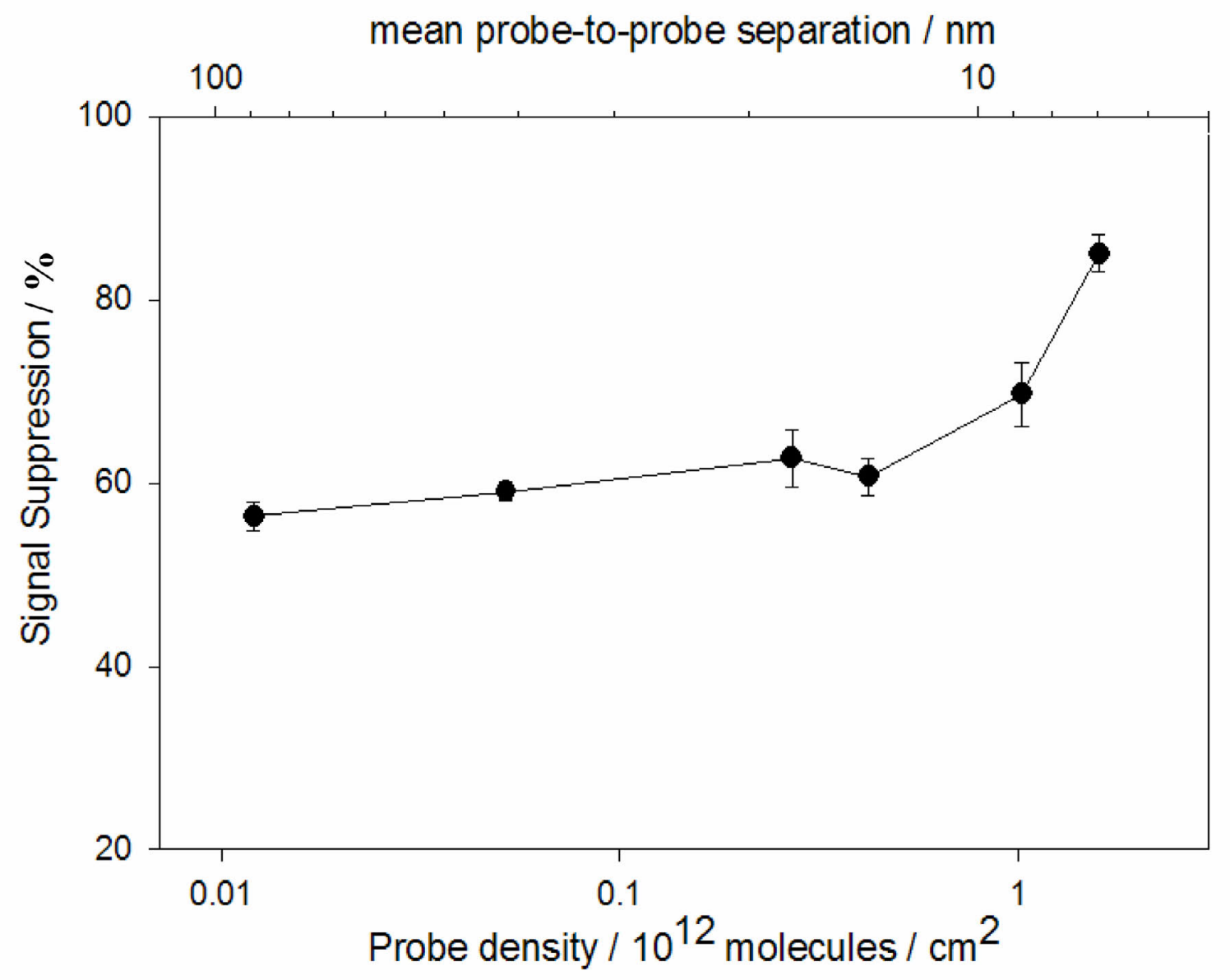

Figure SI3. Probe-density-dependence of linear probe E-DNA signaling is complex. At the saturating probe density of $1.6 \times 10^{12}$ molecules $/ \mathrm{cm}^{2}$ we observe $85 \%$ suppression. Reduction of the probe density to $4.2 \times 10^{11}$ molecules $/ \mathrm{cm}^{2}$ reduces the signal suppression to $60 \%$, a level that is maintained as the probe density drops to the lowest values we can readily measure. The transition between these two regimes is quite sharp: a change in the probe density of $\sim 3$ fold (from $1.6 \times 10^{12}$ to $4.2 \times 10^{11}$ molecules $/ \mathrm{cm}^{2}$ ) gives rise to a 1.5 -fold increase in signal suppression. Shown is the dependence observed at $200 \mathrm{nM}$ target DNA (ST-25). Values represent the average and standard deviation of measurements conducted with three independent sensors at each surface density. 


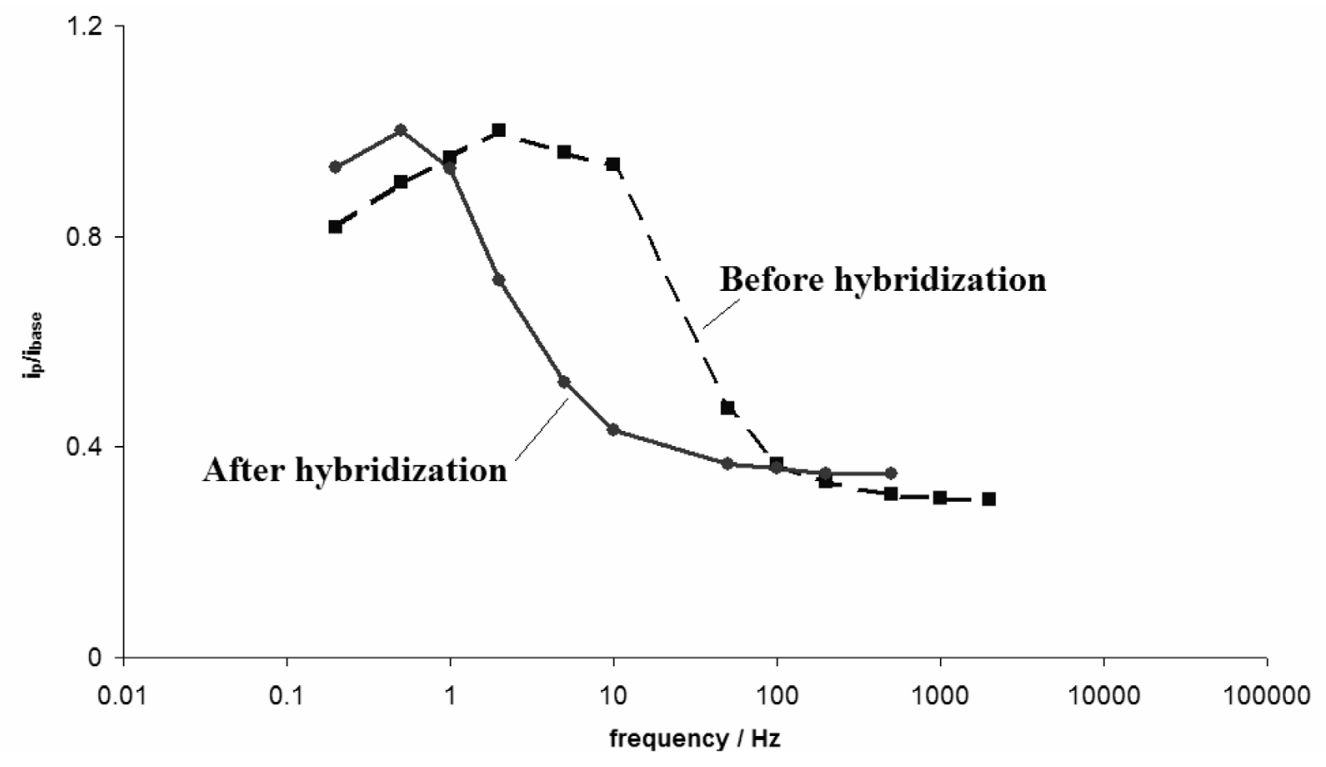

Figure SI4. Observed electron transfer rates differ for hybridized and un-hybridized probes. A sharp change in the slope of the $\mathrm{i}_{\mathrm{p}} / \mathrm{i}_{\text {base }}$ values is observed as the $\mathrm{AC}$ frequency is increased and the electron transfer rate is no longer rapid enough to keep pace with the oscillating applied potential, reflecting the collision-limited transfer rate of the hybridized probe-target duplex.
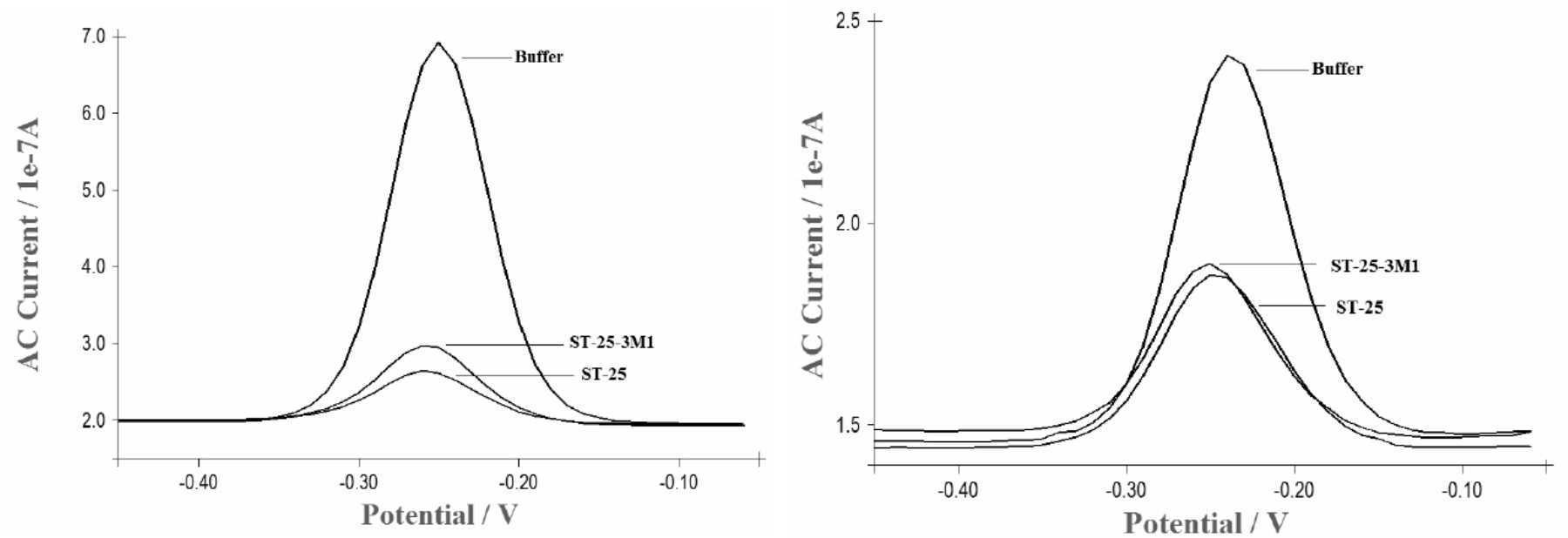

Figure SI5. Specificity of the sensor is somewhat sensitive to probe density. Representative ACVs obtained with high (1.6 x $10^{12}$ molecules $/ \mathrm{cm}^{2}$ - left $)$ and medium $\left(4.2 \times 10^{11}\right.$ molecules $/ \mathrm{cm}^{2}$ - right $)$ density sensors indicate that higher density sensors are better able to discriminate a three-bases mismatched target (ST-25-3M1). 
Table SI3: Probe and target sequences

\begin{tabular}{|c|c|c|c|}
\hline DNA & Sequence $^{a}$ & $\begin{array}{l}\text { Number } \\
\text { of bases }\end{array}$ & Description \\
\hline ST-25 & 5'-GTG GAG AAA TAG AAG AT-3' & 17 & Complementary target with 17 bases \\
\hline ST-25-3M1 & 5'-GTG GAG TTT TAG AAG AT-3' & 17 & Three contiguous mismatches \\
\hline LT-27 & 5'-GCAGT GTG GAG AAA TAG AAG AT TGACG-3' & 27 & Complementary target with 27 bases \\
\hline
\end{tabular}

${ }^{a}$ Underlined bases are those different from the normal target so they indicate mismatches and elongation of the target. Bases in italic are designed to form a structured loop.

BEFORE HYBRIDIZATION

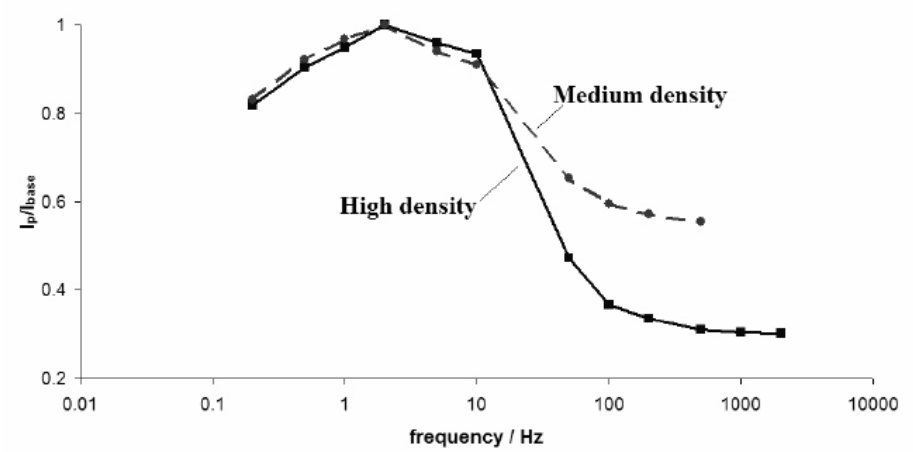

AFTER HYBRIDIZATION

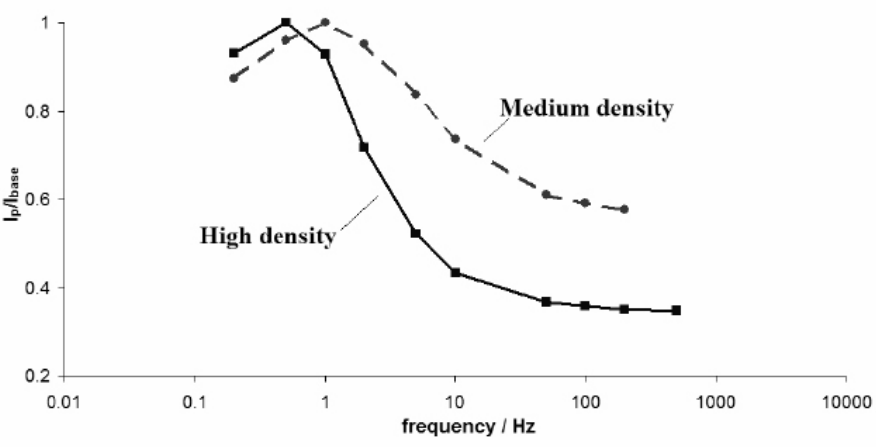

Figure SI6. The dependance of $\mathrm{i}_{\mathrm{p}} / \mathrm{i}_{\text {base }}$ on ACV frequency differs for higher and lower-density sensors. Before hybridization, both high and medium density sensors respond similarly to frequency changes and a comparable electron transfer rate is observed (left). Upon hybridization, the electron transfer rate of higher density sensors is reduced significantly relative to those of medium density sensors, probably accounting for the higher signal suppression observed for the latter (right). This presumably reflects the effects of crowding on the collision rate between the electrochemical label and the electrode surface. 